\title{
O aumento em superfície em Adelia membranifolia (Müll. Arg.) Pax \& K. Hoffm. e Peltophorum dubium (Spreng.) Taub., em resposta ao estresse por deficiência nutricional e alagamento do substrato
}

\author{
ETENALDO F. SANTIAGO ${ }^{1,3}$ e ADELITA A.S. PAOLI ${ }^{2}$
}

(recebido: 14 de agosto de 2002; aceito: 18 de setembro de 2003)

\begin{abstract}
Surface increase in Adelia membranifolia (Müll. Arg.) Pax \& K. Hoffm. and Peltophorum dubium (Spreng.) Taub., in response to stress by flooding and nutritional deficit). Plastic responses in seedlings and young specimens of the native tree species Adelia membranifolia (Müll. Arg.) Paxt. \& K. Hoffm. (Euphorbiaceae) and Peltophorum dubium (Spreng.) Taub. (Leguminosae-Caesalpinoidae), submitted to flooding and nutritional deficit, were studied. Surface increase on the expression module, defined as the region on the stem of the seedling which, under stress situations, undertakes re-differentiation, was measured. The lenticels hypertrophy is seen as its most common morphogenetic expression. In A. membranifolia, both for growth in height and stem diameter and for morphogenic expressions, the association of nutritional stress with flooding represented the most restrictive conditions. In P. dubium nutritional state was more restrictive than flooding for stem growth. In general, nourished plants of both species maintained in a flooded condition reestablished their growth rhythms starting from the third month of treatment, besides evidencing plastic responses such as lenticels hypertrophy and the formation of adventitious roots. In regards to surface increase in the undernourished lots, it was verified that in A. membranifolia, from a total of $38 \%$ of surface, $12 \%$ corresponded to lenticels hypertrophy. In P. dubium the greatest variation of surface increase by lenticels hypertrophy was observed, an increase from 5\% to $13 \%$. Generally, the modular surface in the flooded plants was twice as large when compared to the control group. It is possible that the surface increase, for some species, is significant as a trend towards improving growth stability due to physiological interactions.
\end{abstract}

Key words - expression module, flooding, lenticels, surface increase

RESUMO - (O aumento em superfície em Adelia membranifolia (Müll. Arg.) Pax \& K. Hoffm. e Peltophorum dubium (Spreng.) Taub., em resposta ao estresse por deficiência nutricional e alagamento do substrato). Foram estudadas as respostas plásticas em plântulas e plantas jovens de duas espécies arbóreas nativas, Adelia membranifolia (Müll. Arg.) Pax \& K. Hoffm. (Euphorbiaceae) e Peltophorum dubium (Spreng.) Taub. (Leguminosae-Caesalpinoidae), submetidas ao alagamento do substrado associado ao déficit nutricional. Avaliou-se o acréscimo em superfície no módulo de expressão, definido como a região do eixo da plântula que, sob condições de estresse, sofre rediferenciação sendo considerada a hipertrofia lenticelar como a expressão morfogenética mais comum. Em A. membranifolia a associação do estresse nutricional e alagamento do substrato foi a condição mais restritiva tanto para o crescimento em altura e diâmetro do colo quanto para as expressões morfogenéticas. Já em P. dubium o estado nutricional foi mais restritivo que o alagamento para o crescimento do colo. Em geral, para ambas as espécies, plantas nutridas mantidas alagadas restabeleceram seu ritmo de crescimento a partir do terceiro mês de tratamento, além de expressarem respostas plásticas como a hipertrofia lenticelar e a formação de raízes adventícias. Quanto ao aumento em superfície, nos lotes desnutridos, verificou-se que em A. membranifolia de um total de $38 \%$ de superfície expressa, $12 \%$ corresponderam à hipertrofia lenticelar. Em P. dubium verificou-se as maiores variações de aumento em superfície expressa por hipertrofia lenticelar, elevando de 5\% para 13\%. Em geral a superfície modular nos lotes tratados foi o dobro em relação ao controle. É possível que o aumento em superfície, para algumas espécies, seja significativo como tendência ao aumento da estabilidade no desenvolvimento a partir de interações fisiológicas.

Palavras-chave - alagamento, aumento em superfície, lenticelas, módulo de expressão

\section{Introdução}

No Estado de Mato Grosso do Sul, Brasil, mais especificamente em áreas correspondentes ao complexo

1. Universidade Estadual de Mato Grosso do Sul, Cidade Universitária, Laboratório de Ecologia GASLAB, Caixa Postal 351, 79804-970 Dourados, MS, Brasil.

2. Universidade Estadual Paulista, Instituto de Biociências Departamento de Botânica, Caixa Postal 199, 13506-900 Rio Claro, SP, Brasil.

3. Autor para correspondência: felipe@uems.br
Pantanal ou àquelas associadas a recursos hídricos, são comuns alagamentos periódicos, sobretudo nos períodos de maior pluviosidade (dezembro a fevereiro). Iniciativas visando a recuperação de áreas degradadas nesses biomas requerem um conhecimento não só do fluxo das águas e outros aspectos físico-químicos, como também das respostas dos vegetais em função do alagamento do substrato.

Muitas informações acerca do desenvolvimento de plântulas de espécies nativas em resposta às variações 
ambientais podem ser obtidas a partir de estudos morfológicos. Além das respostas relacionadas ao surgimento ou hipertrofia de lenticelas, outras modificações são observáveis, em especial aquelas relacionadas à morfologia das raízes. O desenvolvimento de aerênquima, corredores de ar ou espaços aéreos descontínuos, o surgimento de raízes adventícias ou com crescimento diageotrópico (Wample \& Reid 1979, Drew et al. 1981, Joly 1996 e Scatena \& Menezes 1996), constituem-se em algumas das respostas expressas por plantas submetidas à hipóxia ou anóxia, condição ambiental freqüentemente encontrada em solos encharcados.

A estabilidade no desenvolvimento (ED), associa as respostas morfogenéticas aos determinantes internos e externos, ou seja, relaciona a geração de determinado fenótipo a complexos de genes coadaptados às pressões ambientais (Freeman et al. 1993). Situações de estresse, de uma maneira geral, tendem a reduzir a capacidade homeostática de um dado sistema (Souza \& Manzatto 2000).

As expressões morfogenéticas de hipertrofia lenticelar em resposta ao estresse por alagamento não estão restritas somente ao caule ou somente à raiz, mas podem ocorrer simultaneamente nestes dois órgãos, portanto, torna-se necessária a delimitação de uma região específica no eixo da planta, na qual são avaliadas as variações em superfície. Em geometria analítica, a maneira mais simples de avaliar medidas de superfície compreende os planos, através de equações lineares contendo apenas as primeiras potências das variáveis $\mathbf{x}, \mathbf{y}$ e $\mathbf{z}$ (Thomas 1969). Em morfogênese é admitida a existência de padrões estruturais, produtos de uma auto organização (Mohr 1982), que determinam, por exemplo, o processo de crescimento por unidades repetitivas, ou módulos (Hallé 1986). Dessa forma, o conceito de módulo ou uma variante, a unidade modular de expressão, parece ser adequado para designar a amplitude $\mathbf{h}$ da função proposta, assegurando a idéia de processo morfológico no espaço e no tempo (Sattler 1996). O módulo de expressão ou região modular é aqui considerada como uma região especifica, obtida através de uma função gerada a partir da interpretação da superfície de um cilindro, o eixo da planta, bem como da superfície gerada pela hipertrofia lenticelar na raiz e no caule.

Embora a hipertrofia lenticelar represente uma resposta morfogenética comum em plantas submetidas ao alagamento do substrato, seu papel no transporte de gases é bastante discutido como resposta adaptativa (Kozlowski 1984, Vartapetian \& Jackson 1997, Botelho et al. 1998, Medri et al. 1998, Rogge et al. 1998, Lobo \& Joly 2000). Assim, o estudo das respostas morfológicas relacionadas com a formação das lenticelas, bem como as variações em superfície provocadas pelo aumento de diâmetro do colo e hipertrofia lenticelar, pode gerar novas informações que contribuam para o melhor conhecimento da influência dessas estruturas sobre o desenvolvimento vegetal em condições de estresse.

Este trabalho objetivou investigar e discutir o valor adaptativo de respostas morfológicas, como o aumento em superfície, verificadas em plântulas e plantas jovens de Adelia membranifolia e Peltophorum dubium, submetidas ao estresse por deficiência nutricional e alagamento do substrato.

\section{Material e métodos}

As sementes de Adelia membranifolia (Müll. Arg.) Pax \& K. Hoffm. e Peltophorum dubium (Spreng.) Taub., provenientes de coletas realizadas em trechos de floresta ciliar nos rios da Prata e Miranda, ambos no município de Jardim-MS/Brasil ( $21^{\circ} 24^{\prime}$ S e $56^{\circ} 22^{\prime}$ W), foram submetidas a secagem prévia e armazenadas sob refrigeração em frascos de vidro.

A expressão de caracteres sob estresse foi avaliada a partir de plântulas com cerca de 30 dias de emergência e plantas jovens com cerca de três a seis meses de desenvolvimento, obtidas diretamente em tubetes de polietileno contendo substrato agrícola Plantimax em viveiro com cobertura sombrite $50 \%$ e irrigação diária por microaspersão. Lotes de plantas $(\mathrm{n}=20$, por espécie com quatro repetições) foram submetidos a quatro tratamentos distintos: Lote A - capacidade de campo/nutrido (CCN): aquele cujas plantas foram submetidas a substrato agrícola Plantimax, mantido em capacidade de campo, adubado com NPK 4:20:20 em solução aquosa a $10 \%, 1 \mathrm{~mL}$ por tubete, 2 vezes por semana nos primeiros dois meses de desenvolvimento e $30 \%$ a partir do segundo mês, e $1 \mathrm{~mL}$ por tubete de solução de micronutrientes (de acordo com especificações do fabricante), quinzenalmente. Lote B - capacidade de campo/desnutrido (CCD): aquele no qual as plantas foram mantidas em substrato drenado, mas sem nenhuma adubação ao longo do período experimental. Lote $\mathrm{C}$ - alagado/nutrido (ALN): lote adubado ao longo do período experimental nas mesmas dosagens que o lote $\mathrm{CCN}$, e mantido nas condições de alagamento sem aeração. $\mathrm{O}$ alagamento foi induzido, em plântulas com trinta dias a partir da emergência em lotes homogênios, em caixas tipo leiteira $(56,5 \times 23 \mathrm{~cm})$; os tubetes foram mantidos suspensos por uma moldura de madeira trançada por fios de nylon n. 80 (figura 1). Este sistema propiciou a manutenção do nível da água na altura da borda dos tubetes. Lote D alagado/desnutrido (ALD): as plântulas não receberam adubação e foram mantidas em substrato alagado ao longo 


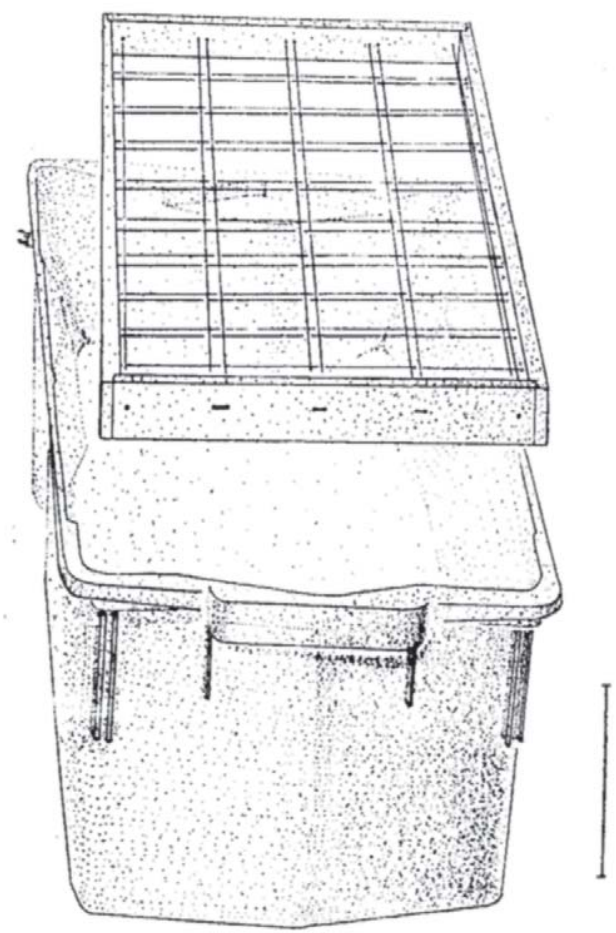

Figura 1. Bandeja para a manutenção do estresse por alagamento do substrato $($ escala $=10 \mathrm{~cm})$.

Figure 1. Tray for flooding treatment $(\mathrm{scale}=10 \mathrm{~cm})$.

do período experimental de seis meses. realizou-se o rodízio periódico das bandejas, alterando-se a posição das plântulas nas bancadas. Não foi efetuada aeração em nenhum tratamento alagado, para a indução da hipóxia.

O estudo morfo-anatômico foi realizado em plântulas com até uma semana após a exposição da raiz primária e plantas jovens a partir do terceiro mês de emergência. Em P. dubium, induziu-se a germinação em sementes escarificadas $\mathrm{com}_{2} \mathrm{SO}_{4}$ por 15 ou 20 minutos considerando o tempo de armazenamento. Nenhum tratamento pré-germinativo foi realizado nas sementes de A. membranifolia. Elas foram colocadas em placa de Petri, forradas com papel de filtro mantido embebido em cerca de $1 \mathrm{~mL}$ de água destilada, e acondicionadas em Câmara de Germinação BOD a $25^{\circ} \mathrm{C}$ sob luz fluorescente branca contínua. A partir de material fresco ou fixado em FAA 50\% (Johansen 1940) foram realizadas secções transversais e longitudinais nas regiões basais do caule e raiz principal, à mão livre e após emblocamento, com auxílio de micrótomo rotatório Reichert-Jung-2040. Foram confeccionadas lâminas provisórias montadas em água destilada e semipermanentes, em glicerina a 50\% (Vasconcelos \& Coutinho 1960) coradas com solução composta por $95 \mathrm{~mL}$ de solução aquosa de azul de astra $1 \%, 5 \mathrm{~mL}$ de solução aquosa de safranina $1 \%$ e 2 gotas de ácido acético, e lâminas permanentes, em historresina JB4 coradas com azul de toluidina 0,05\% montadas em Entelan (Gerrits 1991). As fotomicrografias foram obtidas em fotomicroscópio Olympus BX40.
Os dados biométricos foram obtidos com auxílio de paquímetro eletrônico digital Starrett. Também foram obtidas fotos em estereomicroscópio Zeiss Stemi SV 6.

A análise estatística das variações entre as superfícies médias entre os tratamentos, para cada espécie, foi realizado aplicando-se o teste $t$ para observações pareadas, com 5\% de significância (Vieira \& Hoffmann 1980).

Expressão Modular - O módulo de expressão (Santiago 2002), correspondente a $2 \mathrm{~cm}$ na região do colo das plantas (tabela 1), foi analisado a partir das fórmulas:

Seja:

(1) $\quad \mathrm{P}=2 . \pi \cdot \mathrm{r}$

o perímetro da circunferência.

Derivando-se 1) em relação a $r$

obtivemos:

$$
\text { 2. } \pi \cdot \frac{\mathrm{d}}{2}=\mathrm{C}_{\mathrm{m}}
$$

logo:

(2) $\quad \pi \cdot d=C_{m}$

A partir de $\mathrm{C}_{\mathrm{m}}$ se obteve a superfície modular:

(3)

$$
\mathrm{C}_{\mathrm{m}} \cdot \mathrm{h}=\mathrm{S}_{\mathrm{m}}
$$

Sendo:

d = diâmetro do colo

$\mathrm{h}=$ altura

$\mathrm{C}_{\mathrm{m}}=$ circunferência modular

$\mathrm{S}_{\mathrm{m}}=$ superfície modular

$\pi=$ constante

$\mathrm{r}=$ raio

Já o acréscimo em superfície pelas expressões morfológicas pôde ser obtido por:

a) para lenticelas isoladas

$$
\sum_{i=1}^{n} c_{e} \cdot h_{e}=S_{1}
$$

neste caso $\left(\mathrm{S}_{\mathrm{tl}}=\mathrm{S}_{\mathrm{l}}\right)$

b) quando a expressão lenticelar ocorreu de maneira regular em torno do cilindro modular.

$$
\pi \cdot d_{a}=C_{m l}
$$

A partir de $\mathrm{C}_{\mathrm{ml}}$ se obteve a superfície modular lenticelar

$$
\mathrm{C}_{\mathrm{ml} .} \mathrm{h}=\mathrm{S}_{\mathrm{ml}}
$$

Neste caso $\left(\mathrm{S}_{\mathrm{tl}}=\mathrm{S}_{\mathrm{ml}}\right)$

A partir de (4) e (6) se obteve a superfície lenticelar total para lotes heterogêneos quanto à expressão lenticelar:

$$
\sum_{\mathrm{i}=1}^{\mathrm{n}} \mathrm{S}_{1} \mathrm{~S}_{\mathrm{ml}}=\mathrm{S}_{\mathrm{t}}
$$

Através das médias aritméticas de $\mathrm{S}_{\mathrm{tl}}$ e $\mathrm{S}_{\mathrm{m}}$ se obteve a superfície total expressa:

$$
\mathrm{S}_{\mathrm{tl}}+\mathrm{S}_{\mathrm{m}}=\mathrm{S}_{\mathrm{te}}
$$


Sendo:

$\mathrm{d}_{\mathrm{a}}=$ diâmetro aparente

$\mathrm{C}_{\mathrm{ml}}^{\mathrm{a}}=$ circunferência modular lenticelar

$\mathrm{c}_{\mathrm{e}}=$ comprimento lenticelar expresso

$\mathrm{h}_{\mathrm{e}}=$ largura lenticelar expressa

$\mathrm{S}_{1}=$ superfície lenticelar expressa

$\mathrm{S}_{\mathrm{ml}}=$ superfície modular lenticelar

$\mathrm{S}_{\mathrm{t} 1}=$ superfície total lenticelar

$\mathrm{S}_{\mathrm{te}}=$ superfície total expressa

Tabela 1. Parâmetros para a avaliação da superfície modular em plântulas e plantas jovens. $\mathrm{h}=$ altura modular $(2 \mathrm{~cm}), \mathrm{d}=$ diâmetro do colo, $\mathrm{C}_{\mathrm{e}}=$ comprimento lenticelar expresso, $\mathrm{h}_{\mathrm{e}}=$ largura lenticelar expressa.

Table 1. The surface modular avaliation parameters in seedlings and young plants. $\mathrm{h}=$ modular height $(2 \mathrm{~cm}), \mathrm{d}=$ stem diameter, $\mathrm{C}_{\mathrm{e}}=$ lenticelar expressed length, $\mathrm{h}_{\mathrm{e}}=$ lenticelar expressed width.

\begin{tabular}{lll}
\hline Parâmetro avaliado & Fórmula & Unidade \\
\hline Circunferência modular $\left(\mathrm{C}_{\mathrm{m}}\right)$ & $\mathrm{p} \cdot \mathrm{d}$ & $\mathrm{cm}$ \\
Superfície modular $\left(\mathrm{S}_{\mathrm{m}}\right)$ & $\mathrm{C}_{\mathrm{m}} \cdot \mathrm{h}$ & $\mathrm{cm}^{2}$ \\
Superfície lenticelar $\left(\mathrm{S}_{\mathrm{l}}\right)$ & $\sum_{\mathrm{i}=1}^{\mathrm{m}} \mathrm{c}_{\mathrm{e}} \cdot \mathrm{h}_{\mathrm{e}}$ & $\mathrm{cm}^{2}$ \\
Superfície modular lenticelar $\left(\mathrm{S}_{\mathrm{ml}}\right)$ & $\mathrm{C}_{\mathrm{ml}} \cdot \mathrm{h}$ & $\mathrm{cm}^{2}$ \\
Superfície total lenticelar $\left(\mathrm{S}_{\mathrm{tl}}\right)$ & $\sum_{\mathrm{i}=1}^{\mathrm{S}} \mathrm{S}_{1}+\mathrm{S}_{\mathrm{ml}}$ & $\mathrm{cm}^{2}$ \\
Superfície total expressa $\left(\mathrm{S}_{\mathrm{te}}\right)$ & $\mathrm{S}_{\mathrm{tl}}+\mathrm{S}_{\mathrm{m}}$ & $\mathrm{cm}^{2}$ \\
\hline
\end{tabular}

\section{Resultados}

Através da secção transversal do caule de plantas de A. membranifolia (lote CCD) com três meses de idade, evidenciou-se o crescimento secundário e uma relativa regularidade na disposição dos tecidos, caracterizada pela presença de epiderme e parênquima cortical interrompido por 1-2 fileiras de fibras que limitam o floema (figura 2). Os elementos do xilema limitam um parênquima medular rico em grãos de amido (figura 3). Nos lotes ALN o início da hipertrofia lenticelar é notada nos primeiros 3-5 dias após o alagamento, ao passo que nos lotes ALD foi verificada, em geral, entre 8-10 dias. Em ambos os lotes alagados, verificou-se a diferenciação das células do felogênio da lenticela (figura 4).

Em P. dubium, durante o crescimento secundário, a atividade cambial promoveu a formação de um anel de 1-2 camadas de fibras esclerenquimáticas unindo os quatro conjuntos de fibras primariamente associadas aos feixes vasculares. Secções transversais em plantas do lote CCD, por volta do terceiro mês, mostraram epiderme com tricomas pluricelulares. Foi comum a ocorrência de lenticelas sem fibras associadas, xilema secundário bem desenvolvido, limitando parênquima medular rico em grãos de amido (figura 5). No lote ALD por volta do segundo mês de tratamento, foi visível a hipertrofia lenticelar (figura 6) que, embora de formação similar a A. membranifolia, ocorreu preferencialmente na região entre os feixes de fibras.

Em A. membranifolia verificou-se que, mantidas as condições de saturação do substrato, as divisões periclinais das células do felogênio da lenticela se intensificam, sofrem alongamento, surgindo, assim, expansões de tecido lenticelar frouxo (figuras 7-9). As lenticelas hipertrofiadas são evidenciadas na epiderme a partir do colapso das células do primeiro ao último estrato, este efeito é potencializado por divisões periclinais nas células do felogênio da lenticela em alguns pontos (figuras 4-9).

Para ambas as espécies, ficou evidente a influência do estado nutricional na expressão de raízes adventícias uma vez que só ocorreram nos lotes nutridos (ALN). Estas estruturas tornaram-se evidentes a partir do terceiro mês de alagamento.

De maneira geral, ambas as espécies testadas apresentaram diferentes respostas em função da combinação de estresse nutricional e alagamento do substrato ao longo do período de seis meses. Em A. membranifolia, pela análise da contribuição percentual em altura $(\mathrm{cm})$ das plantas (figura 10A), verificou-se que a associação de estresse desnutrição/ alagamento encontrado nos lotes ALD, foi a mais restritiva, passando de $31,1 \%$ para cerca de $17,1 \%$ aos seis meses de tratamento. As menores médias mensais de altura também foram verificadas nos lotes ALD (tabela 2). Observando a figura 10A, verifica-se que as plantas dos lotes ALN restabeleceram seu ritmo de crescimento a partir do terceiro mês de tratamento, chegando aos melhores resultados juntamente com as plantas dos lotes CCN (34,5\% e $28 \%$, respectivamente).

No que diz respeito ao diâmetro do colo, o aumento percentual maior foi encontrado em ALN 29, $1 \%$ (figura 10B). Comparado aos demais tratamentos, ALD sofreu uma redução percentual para $22,2 \%$, no entanto, a variação das médias não foi estatisticamente significativa (tabela 2).

Em $P$. dubium, as diferenças médias de altura e diâmetro do colo entre os tratamentos foram significativas. As menores médias de crescimento em altura (tabela 2), e redução na contribuição percentual nas taxas de crescimento médio entre os tratamentos (figura 11A), foram observadas em CCD. Os lotes CCD apresentaram os menores valores médios mensais de diâmetro do colo $(17,1 \%)$, e redução na contribuição 

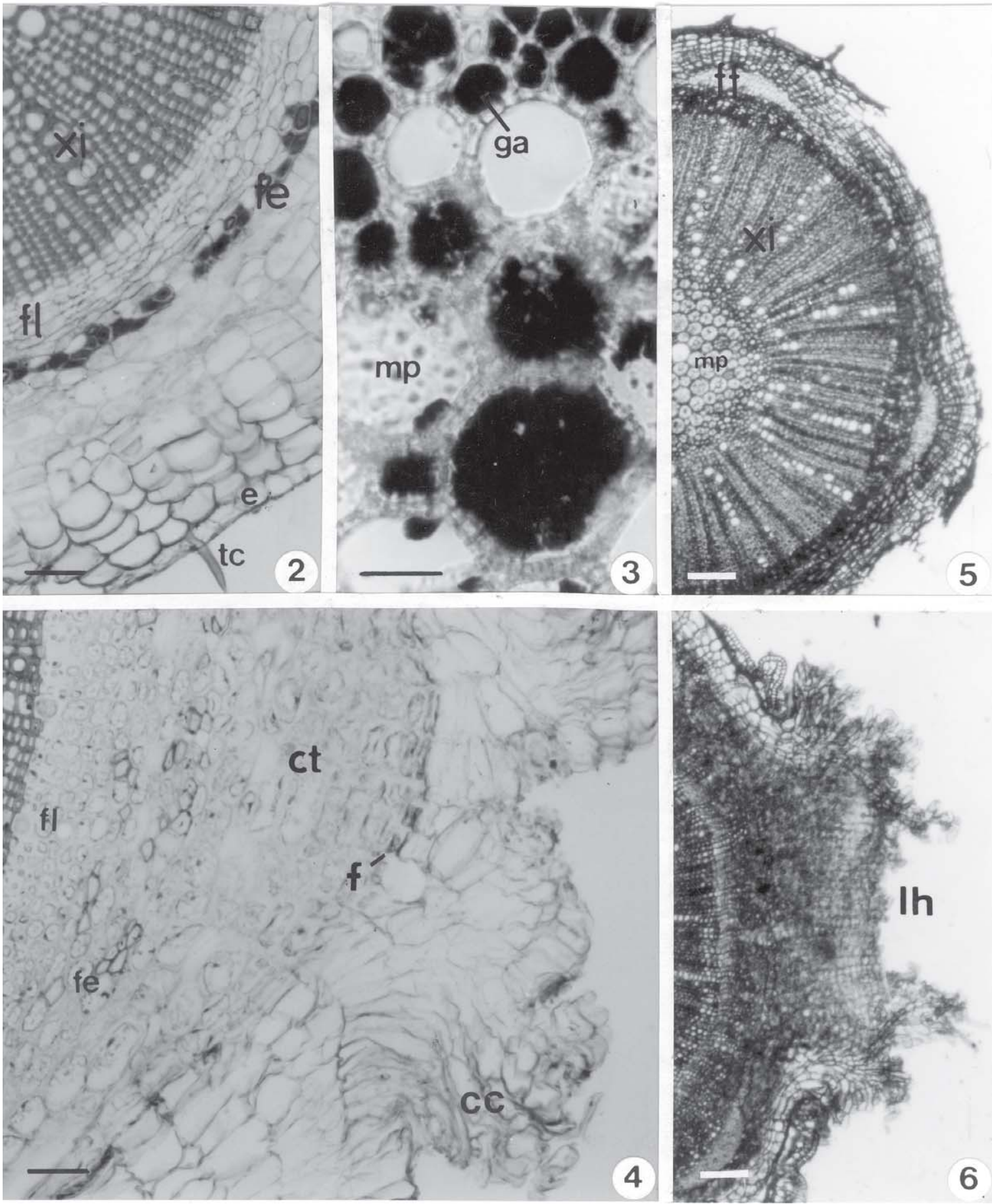

Figura 2. Secção transversal em caule de planta jovem de Adelia membranifolia, lote CCD. Figura 3. Detalhe da região medular evidenciando a reserva de amido. Figura 4. Detalhe do início da hipertrofia lenticelar, lote ALD. Figura 5. Secção transversal em caule de planta jovem de Peltophorum dubium, lote CCD. Figura 6. Hipertrofia lenticelar, lote ALD. (cc = célula colapsada, $\mathrm{ct}=$ córtex, $\mathrm{e}=$ epiderme, $\mathrm{f}=$ felogênio, $\mathrm{fe}=$ fibras esclerenquimáticas, $\mathrm{ff}=$ feixe de fibras, $\mathrm{fl}=$ floema, $\mathrm{ga}=$ grãos de amido, $\mathrm{lh}=$ lenticela hipertrofiada, $\mathrm{mp}=$ medula parenquimática, $\mathrm{tc}=$ tricoma, $\mathrm{xi}=\mathrm{xilema})$. Barras $=2 \mu \mathrm{m}(3), 5 \mu \mathrm{m}(2,4), 10 \mu \mathrm{m}(5,6)$.

Figure 2. Transversal section of the stem in young specimens of the native trees Adelia membranifolia, lot CCD. Figure 3. Detail of the medular portion to show the startch reserve. Figure 4. Initial stage of the lenticels hypertrophy, lot ALD. Figure 5. Transversal section of the stem in young plant Peltophorum dubium, lot CCD. Figure 6. Lenticels hypertrophy, lot ALD. $(\mathrm{cc}=$ compress cells, $\mathrm{ct}=$ cortical region, $\mathrm{e}=$ epiderms, $\mathrm{f}=$ phellogen, $\mathrm{fe}=$ sclerenchyma fibers, $\mathrm{ff}=$ blunde fibers, $\mathrm{fl}=\mathrm{floem}, \mathrm{ga}$ $=$ starch grain, $\mathrm{lh}=$ lenticel hypertrophy, $\mathrm{mp}=$ parenchyma marrow, $\mathrm{tc}=$ hair, $\mathrm{xi}=\mathrm{xylem})$. Bars $=2 \mu \mathrm{m}(3), 5 \mu \mathrm{m}(2,4), 10 \mu \mathrm{m}(5,6)$. 

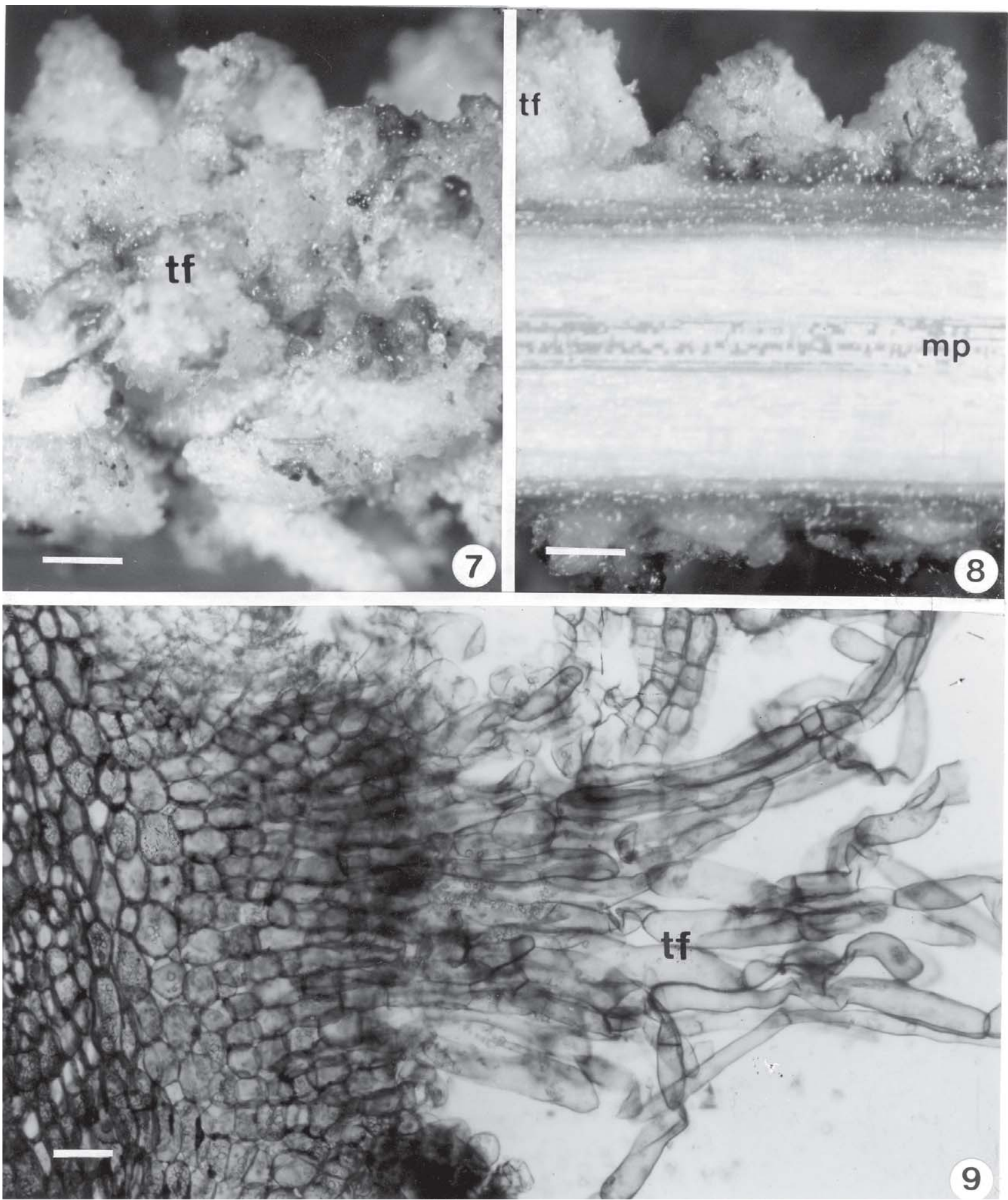

Figura 7. Caule de planta jovem de Adelia membranifolia. Visão da superfície do caule evidenciando o tecido frouxo associado às lenticelas hipertrofiadas. Figura 8. Secção longitudinal da mesma região do caule da figura anterior. Figura 9. Detalhe das células do tecido frouxo associado à lenticela hipertrofiada. $(\mathrm{mp}=$ medula parenquimática, $\mathrm{tf}=$ tecido frouxo associado). Barras $=5 \mu \mathrm{m}(9), 0,5 \mathrm{~mm}(7,8)$.

Figure 7. Stem in young specimens of the native trees Adelia membranifolia. Surface of the stem to show the tissue weak associated whith lenticels hypertrophy. Figure 8. Longitudinal section of the same stem portion. Figure 9. Detail of the cells in tissue weak associated whith lenticels hypertrophy. $(\mathrm{mp}=$ parenchyma marrow, $\mathrm{tf}=$ tissue weak). Bars $=5 \mu \mathrm{m}(9), 0,5 \mathrm{~mm}(7,8)$. 

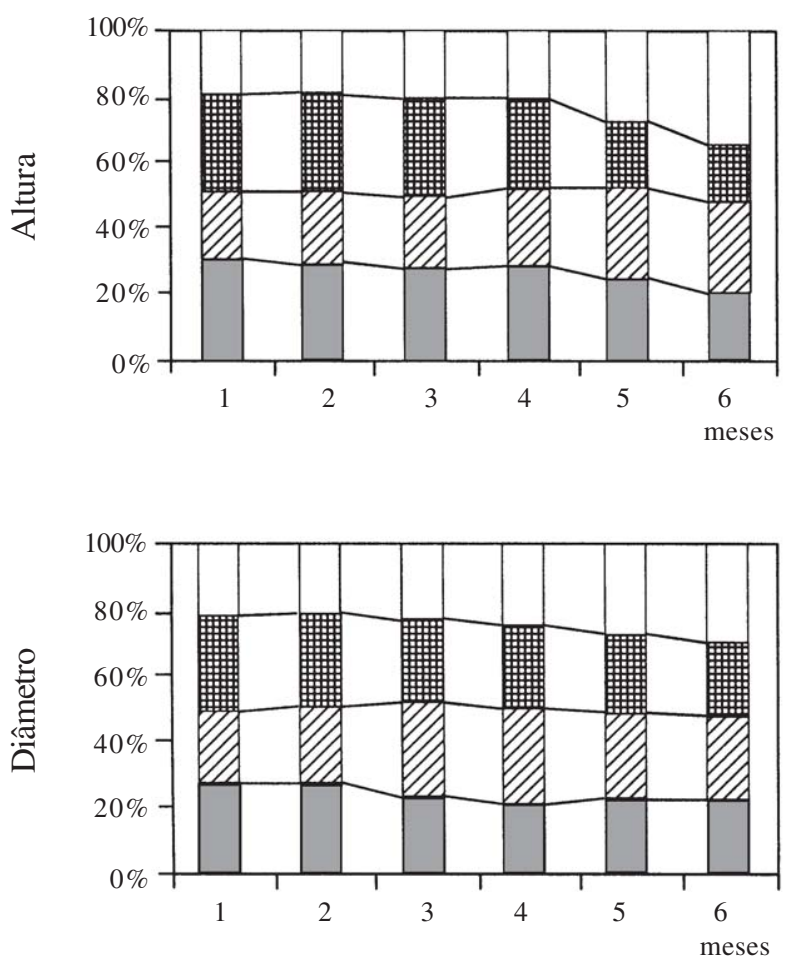

B

Figura 10. Contribuição percentual para os valores médios em altura (cm) (A) e diâmetro do colo ( $\mathrm{mm})(\mathrm{B})$ para plantas de Adelia membranifolia submetidas ao estresse. (ALD = alagamento desnutrido, $\mathrm{ALN}=$ alagamento nutrido, $\mathrm{CCD}=$ capacidade de campo desnutrido e $\mathrm{CCN}=$ capacidade de

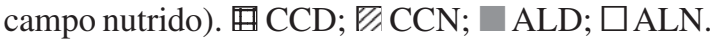

Figure 10. Percentual contribution for growth in height $(\mathrm{cm})$ (A) and stem diameter (mm) (B) in Adelia membranifolia plants under stress. $(\mathrm{ALD}=$ undernourished flooded, $\mathrm{ALN}=$ nourished flooded, $\mathrm{CCD}=$ drain soil undernourished and $\mathrm{CCN}$

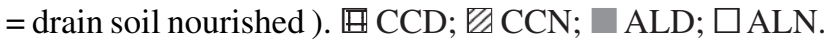

percentual ao longo do período experimental (figura 11B). As maiores médias e aumento na contribuição percentual entre os tratamentos foram verificadas em CCN e ALN, (respectivamente, $29 \%$ e $30,1 \%$ ).

Em A. membranifolia, comparando a contribuição percentual das médias de superfície nos lotes desnutridos (figura 12A), verificou-se que $23 \%$ corresponderam ao controle, ao passo que a superfície total expressa correspondeu a $38 \%$, dos quais $12 \%$ corresponderam à hipertrofia lenticelar. Nos lotes nutridos (figura 12B) a superfície total expressa foi praticamente o dobro da superfície do controle ( $40 \%$ contra $21 \%$ ), a expressão lenticelar contribuiu com $14 \%$ do total expresso. Independentemente do estado nutricional, as maiores médias em superfície modular (figura 13A, B) foram verificadas nas plantas alagadas (Smt).
A

Tabela 2. Valor médio mensal de altura $(\mathrm{cm})$ e diâmetro médio do colo $(\mathrm{mm})$ de plantas submetidas a estresse. $($ ALD $=$ alagamento desnutrido, $\mathrm{ALN}=$ alagamento nutrido, $\mathrm{CCD}=$ capacidade de campo desnutrido, $\mathrm{CCN}=$ capacidade de campo nutrido, $\mathrm{C}=$ controle, $\mathrm{T}=$ tratamento). Valores seguidos de mesma letra, em coluna, não diferem significativamente entre si.

Table 2. Means values monthly of stem height $(\mathrm{cm})$ and stem diameter $(\mathrm{mm})$ in stressed plants. $(\mathrm{ALD}=$ undernourished flooded, $\mathrm{ALN}=$ nourished flooded, $\mathrm{CCD}=$ drain soil undernourished, $\mathrm{CCN}=$ drain soil nourished, $\mathrm{C}=$ control, $\mathrm{T}=$ stressed). Values followed by the same letters, in columns, are not significantly different.

\begin{tabular}{lrrrrr}
\hline Lotes & \multicolumn{2}{c}{ Adelia membranifolia } & \multicolumn{2}{c}{ Peltophorum dubium } \\
\cline { 2 - 3 } & $\begin{array}{c}\text { altura } \\
(\mathrm{cm})\end{array}$ & $\begin{array}{c}\text { diâmetro } \\
(\mathrm{mm})\end{array}$ & & $\begin{array}{c}\text { altura } \\
(\mathrm{cm})\end{array}$ & $\begin{array}{c}\text { diâmetro } \\
(\mathrm{mm})\end{array}$ \\
\hline $\mathrm{CCD}(\mathrm{C})$ & $10,26 \mathrm{a}$ & $2,12 \mathrm{a}$ & & $7,75 \mathrm{a}$ & $2,06 \mathrm{a}$ \\
$\mathrm{ALD}(\mathrm{T})$ & $9,85 \mathrm{a}$ & $2,17 \mathrm{a}$ & $8,85 \mathrm{~b}$ & $2,79 \mathrm{~b}$ \\
$\mathrm{CCN}(\mathrm{C})$ & $10,82 \mathrm{a}$ & $2,34 \mathrm{a}$ & & $11,28 \mathrm{c}$ & $2,96 \mathrm{~b}$ \\
$\mathrm{ALN}(\mathrm{T})$ & $10,98 \mathrm{a}$ & $2,23 \mathrm{a}$ & & $10,27 \mathrm{cb}$ & $2,78 \mathrm{ab}$ \\
\hline
\end{tabular}

Em P. dubium verificou-se um significativo aumento da superfície lenticelar expressa ( $5 \%$ nos lotes desnutridos contra $13 \%$ nos lotes nutridos) em função do estado nutricional das plantas (figura 12C, D). As maiores médias foram verificadas nas plantas alagadas, sendo que as diferenças entre as médias do controle e do tratamento também foram maiores nos lotes desnutridos (figura 14A, B).

\section{Discussão}

A expressão da hipertrofia lenticelar em resposta ao alagamento do substrato, de maneira geral, foi semelhante em ambas as espécies testadas, corroborando a clássica definição de arranjo celular de tecido frouxo protuso à epiderme (Morretes \& Venturelli 1985). Quanto à origem, aparentemente segue o mesmo padrão para diferentes espécies ou tratamentos associados ao alagamento (Rubin Filho 1997, Medri et al. 1998, Botelho et al. 1998), ou seja, divisões periclinais nas células do felogênio da lenticela.

Pouca ou nenhuma atenção tem sido dada ao tecido frouxo associado à lenticela, que na maioria das preparações anatômicas é perdido, sendo descrita apenas a abertura lenticelar. As células deste tecido, embora guardem algumas semelhanças estruturais com outros tipos celulares, como as hifas de fungos, tubos polínicos ou pêlos radiciais, diferem destes quanto à 


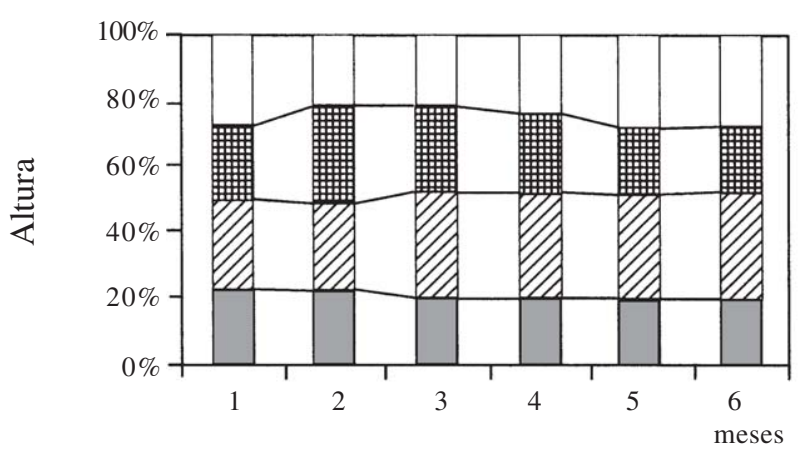

B

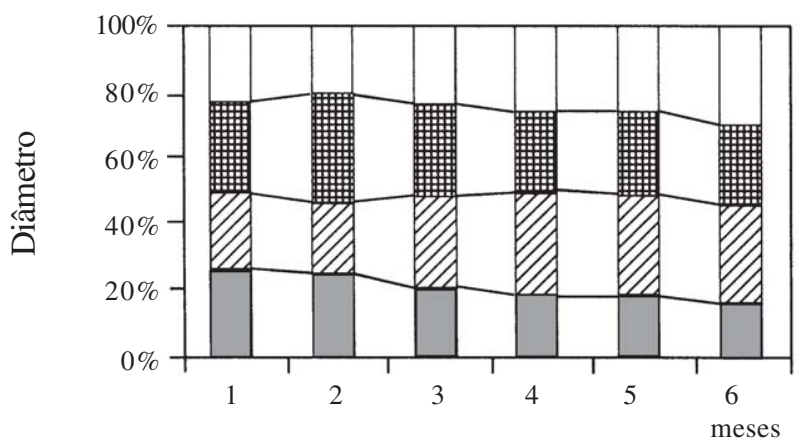

Figura 11. Contribuição percentual para os valores médios em altura $(\mathrm{cm})(\mathrm{A})$ e diâmetro do colo $(\mathrm{mm})(\mathrm{B})$ para plantas de Peltophorum dubium submetidas ao estresse. $(\mathrm{ALD}=$ alagamento desnutrido, ALN = alagamento nutrido, $\mathrm{CCD}=$ capacidade de campo desnutrido e $\mathrm{CCN}=$ capacidade de

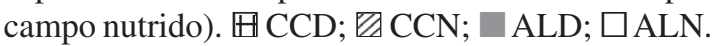

Figure 11. Percentual contribution for growth in height $(\mathrm{cm})$ (A) and stem diameter ( $\mathrm{mm})(\mathrm{B})$ in Peltophorum dubium plants under stress. (ALD $=$ undernourished flooded, $A L N=$ nourished flooded, $\mathrm{CCD}=$ drain soil undernourished and $\mathrm{CCN}$ $=$ drain soil nourished ). 田 CCD; $₫ \mathrm{CCN}$; ALD; $\square \mathrm{ALN}$.

formação e aspectos funcionais. Peterson \& Farquhar (1996) e outros autores descreveram o chamado "crescimento de topo" para os pêlos radiciais. Este crescimento pressupõe uma polarização do protoplasma celular responsável pela deposição das microfibrilas de celulose na parede primária no topo da célula. Observando o crescimento do tecido frouxo associado à abertura lenticelar (figura 9), nota-se a perda de protoplasma das células na medida em que se afastam do parênquima cortical, o que descaracterizaria o "crescimento de topo".

Segundo Kutschera (1991), a estrutura primária da parede celular é capaz de responder a deformações elásticas (reversíveis) ou plásticas (irreversíveis). Citando trabalhos clássicos, atesta o papel da pressão de turgor como um pré-requisito para o alongamento celular e a duração do estresse como um fator determinante da natureza da resposta. Evidentemente, o alongamento celular observado na hipertrofia lenticelar não é explicado somente sob o ponto de vista mecânico, cabendo ao etileno (Medri et al. 1998) e à auxina (Kutschera 1991) a participação nesta resposta ao estresse por alagamento.

Se considerarmos a orientação das divisões celulares do tecido frouxo associado, bem como a perda de conteúdo celular, é razoável supor que, sob influência hormonal e aumento de turgor, o crescimento ocorre a partir do parênquima cortical para fora da abertura lenticelar, sendo, portanto caracteristicamente mais basal que apical. A baixa densidade do tecido frouxo associado é decorrente do alongamento celular e de inúmeros espaços intercelulares presentes.

Considerações acerca da participação das lenticelas hipertrofiadas no transporte de oxigênio para as raízes e conseqüente recuperação da respiração aeróbica, foram levantadas por Lobo \& Joly (2000), Botelho et al.

A

B
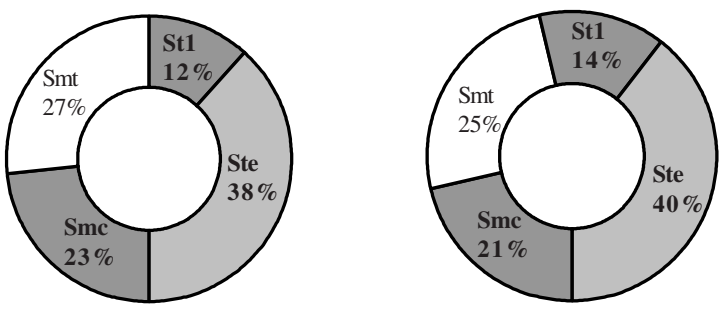

C

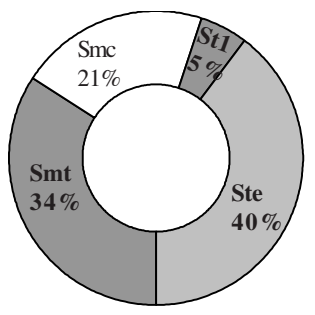

$\mathrm{D}$

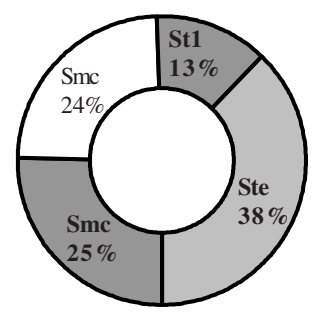

Figura 12. Variação em superfície modular para plantas submetidas a estresse: Adelia membranifolia - lote desnutrido (A), lote nutrido (B), Peltophorum dubium - lote desnutrido (C), lote nutrido (D). ( $\mathrm{Smc}=$ Superfície modular controle, $\mathrm{Smt}=$ Superfície modular do tratamento, $\mathrm{Stl}=$ Superfície total lenticelar, Ste $=$ Superfície total expressa).

Figure 12. Modular surface changes in plants under stress: Adelia membranifolia - undernourished lot (A), nourished lot (B), Peltophorum dubium - undernourished plot (C), nourished plot (D). (Smc $=$ Modular surface control, $\mathrm{Smt}=$ Modular surface stressed, Stl = Lenticels whole surface, Ste $=$ Whole surface expressed). 
(1998), Medri et al. (1998), Rogge et al. (1998) e outros. Para Botelho et al. (1998) a expressão da hipertrofia lenticelar em condições de hipóxia ou anóxia no meio alagado, paradoxalmente, está relacionada à presença de oxigênio na superfície da água, daí a concentração dessas estruturas na região caulinar próxima à superfície da água. No entanto, alguns autores preferem evitar as generalizações acerca da hipertrofia lenticelar, admitindo que, para algumas espécies, as lenticelas hipertrofiadas e aerênquima são resultados de desbalanço hormonal (Joly 1996), não estando relacionadas diretamente com
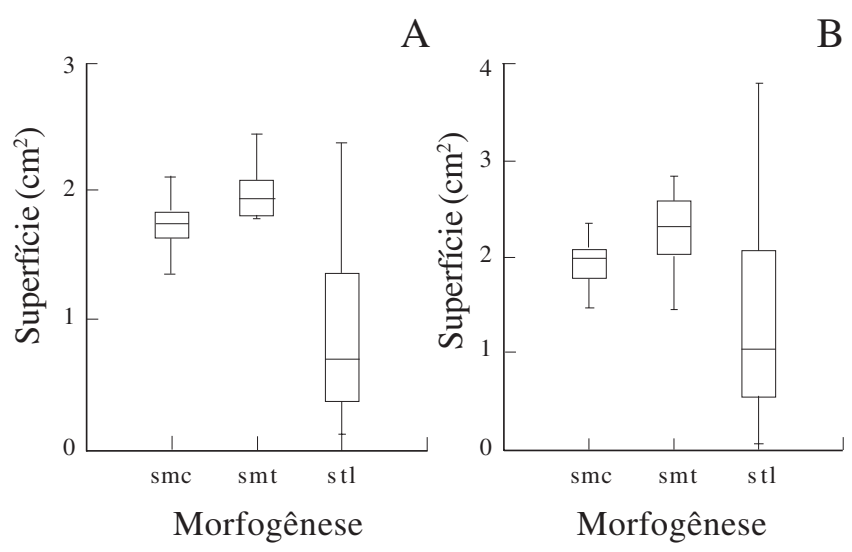

Figura 13. Variação média e desvio padrão da superfície modular em plantas de Adelia membranifolia submetidas a estresse.

Figure 13. Modular surface mean variation and standard deviation in Adelia membranifolia stressed plants.
A

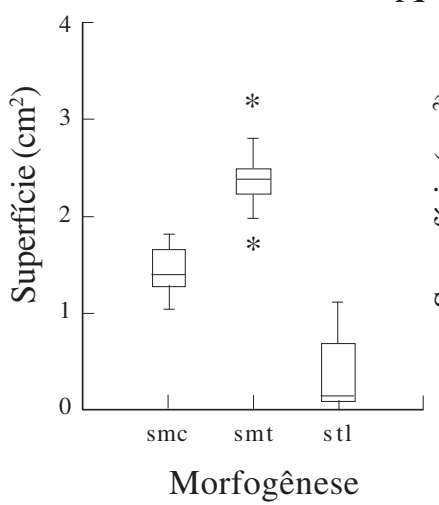

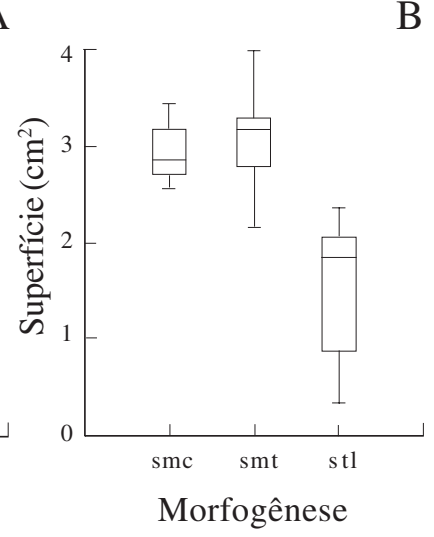

Figura 14. Os mesmos parâmetros em plantas de Peltophorum dubium. A. Lote desnutrido. B. Lote nutrido. (Smc = Superfície modular controle, $\mathrm{Smt}=$ Superfície modular do tratamento, $\mathrm{Stl}=$ Superfície total lenticelar, $\mathrm{Ste}=$ Superfície total expressa).

Figure 14. The same parameters in Peltophorum dubium stressed plants. A. undernourished lot. B. nourished lot. (Smc = Modular surface control, Smt = Modular surface stressed, Stl = Lenticels whole surface, Ste $=$ Whole surface expressed). a difusão de oxigênio do sistema aéreo para o sistema radicial, mas sim à saída de compostos voláteis como o etileno, o etanol e o acetaldeído (Kozlowski 1984, Joly 1996). No que diz respeito à morfoanatomia, parece claro que os eventos relacionados à formação do tecido frouxo associado à abertura lenticelar culminam no alongamento celular, perda de conteúdo celular, perda de adesão nas paredes anticlinais, morte de células e formação de espaços intercelulares. Estes eventos conferem ao tecido um aspecto esponjoso de baixa densidade, o que em potencial, favoreceria a passagem de gases.

Para as espécies testadas, o aumento na contribuição percentual em altura e diâmetro do colo, tanto nas condições alagadas quanto em capacidade de campo, reflete que o estresse nutricional foi mais restritivo que o alagamento do substrato, ou seja, a manutenção do crescimento em condições de alagamento do substrato dependeu do estado nutricional das plantas. Dessa forma, plantas dos lotes nutridos apresentaram maior e mais rápida resposta de hipertrofia lenticelar quando comparadas aos lotes desnutridos, além do que, somente plantas nutridas expressaram raízes adventícias. Andrade et al. (1999) também verificaram diferentes respostas de crescimento em função do tratamento e da espécie. Segundo Janiesch (1991), as respostas das raízes à anaerobiose são fortemente dependentes de um suprimento adequado de macro e micronutrientes, sem os quais são observadas alterações severas nas taxas de crescimento. Medri et al. (1998) descreveram o aumento do diâmetro do colo e hipertrofia lenticelar para $P$. dubium, não encontrando, no entanto, as raízes adventícias.

Em nosso estudo, verificamos que os dois fatores estressantes atuando em conjunto foram mais efetivos como limitadores de crescimento, e que o incremento em diâmetro do colo, nos primeiros meses de alagamento, nos lotes desnutridos (figuras 10B, 11B) pode refletir uma inicial otimização na alocação de recursos que, no entanto, não foram suficientes para a manutenção do crescimento ao longo de todo o período experimental. A hipótese de alocação compensatória prediz maior flexibilidade de respostas de crescimento em plantas melhor nutridas (Sharpe \& Rykiel 1991). Evidentemente, a capacidade de ajustar as interações nas vias metabólicas em função das variações ambientais é dependente do potencial genético de cada espécie (Pahlich 1993). Scatena \& Menezes (1996), estudando espécies de Paepalanthus, sugerem a ocorrência de variações intrapopulacionais para explicar a plasticidade de algumas respostas morfogênicas. 
Rogge et al. (1998), discutindo as variações entre os resultados obtidos por outros autores, defenderam que o alagamento possivelmente promove diferentes respostas metabólicas entre as populações. A ocorrência de variações intrapopulacionais nas respostas morfogênicas, fisiológicas e no desenvolvimento corroboram com os princípios encontrados em Barbosa et al. (1997) e Barbosa (2000), no que diz respeito à produção local de mudas para a recuperação de áreas degradadas, sobretudo se tais variações levarem a interações adaptativas.

Além do estado nutricional, outros fatores normalmente estão associados às respostas de crescimento, como, por exemplo, a irradiância, o nível da água, o tempo de duração do alagamento, (Rubin Filho 1997, Parolin 2001). A capacidade de manutenção do crescimento em altura sob condições de alagamento do substrato pode ser fundamental para a sobrevivência da planta, sobretudo se representar a fuga da submersão total.

Sob influência do estado nutricional, as condições de alagamento em geral podem representar aumento ou redução na altura média e no diâmetro médio do colo das plantas. Entretanto, inferências acerca da adaptabilidade de uma espécie às condições de alagamento do substrato, baseadas em poucas variáveis, devem ser tomadas com reserva mesmo porque a sobrevivência em condições de alagamento pode envolver uma associação de mudanças morfoanatômicas e fisiológicas, bem como admitir as variações interespecíficas ou populacionais (Rogge et al. 1998, Lobo \& Joly 2000, Parolin 2001).

Observando-se a figura 12, nota-se a diferença real entre as superfícies expressas pelos lotes controle e tratamento. Tanto $P$. dubium quanto A. membranifolia sofreram um significativo aumento em superfície na região mais sujeita a exercer trocas gasosas, a superfície modular. Esses dados, aliados aos dados de crescimento, indicam a aptidão dessas duas espécies para tolerar as condições testadas, o que nos leva a analisar com cautela as classificações de tolerância que não consideram o estádio de desenvolvimento da planta, o estado nutricional, o nível de submersão, a associação de fatores estressantes (como luz, por exemplo) e o tempo de alagamento, entre outros.

Da mesma forma que o desenvolvimento dos pelos radiciais teoricamente aumentam a superfície de absorção das raízes (Peterson \& Farquhar 1996), neste trabalho, admitimos que o aumento em superfície no módulo de expressão potencialmente aumentaria a superfície capaz de realizar as trocas gasosas nas condições de alagamento do substrato. Dessa forma, o acréscimo em superfície no módulo de expressão, associado a outras variáveis, representa mais uma ferramenta na investigação de padrões de expressão morfológica em resposta às condições de alagamento do substrato.

Nas formações florestais associadas a corpos d'água, admite-se a ocorrência de espécies capazes de responder à saturação do substrato, através de expressões morfogenéticas que envolvem diferenciação e rediferenciação de tecidos maduros. Considerando-se que a evolução se processa à luz da seletividade, através de estádios que são altamente adaptativos e competitivos (Mohr 1982, Vartapetian \& Jackson 1997), é de se esperar que estas respostas plásticas desenvolvam valor adaptativo ao longo do processo de seleção natural. Cabe lembrar que a simples ocorrência da hipertrofia lenticelar, bem como o aumento em superfície, não devem ser encarados isoladamente como adaptação ou tolerância às condições de alagamento, no entanto, é possível que o aumento em superfície e a hipertrofia lenticelar, para algumas espécies, seja significativo como tendência ao aumento da estabilidade no desenvolvimento a partir de interações fisiológicas.

\section{Referências bibliográficas}

ANDRADE, A.C.S., RAMOS, F.N., SOUZA, A.F., LOUREIRO, M.B. \& BASTOS, R. 1999. Flooding effects in seedlings of Cytharexillum myrianthum Cham. and Genipa americana L.: responses of two neotropical lowland tree species. Revista Brasileira de Botânica 22:281-285.

BARBOSA, L.M., ASPERTI, L.M. \& DE VUONO, Y.S. 1997. Native species performance in restored forest in an area degraded by cultivation (São Paulo-Brasil). In Proceedings of the International Symposium on Assessment and Monitoring of Forests in Tropical Dry Regions With Special Reference to Gallery Forests. Universidade de Brasília, Brasília, p.351-364.

BARBOSA, L.M. 2000. Princípios da recuperação vegetal de áreas degradadas. Manual. Secretaria de Estado de Meio Ambiente, São Paulo.

BOTELHO, M.N., OLIVEIRA, L.E.M., OLIVEIRA, M.L. \& CARVALHO, C.J.R. 1998. Adaptação morfo-anatômica de plantas jovens de Inga vera Willd. e Virola surinamensis (Rolland. ex Rottb.) Warb. à submersão. Boletim do Museu Paraense Emílio Goeldi, série Botânica 14:93-107.

DREW, M.C., JACKSON, M.B., JIFFARD, S.C. \& CAMPBEL, R. 1981. Inhibition by silver ions of gas space (aerenchyma) formation in adventitious roots of Zea mays L. subjected to exogenous ethylene or to oxygen deficiency. Planta. 153:217-224. 
GERRITS, P.O. 1991. The application of glycol methacrylate in histotechnology, some fundamental principles. State University Groningen, Groningen.

FREEMAN, D.C., GRAHAM, J.H. \& EMLEN, J.M. 1993. Developmental stability in plants: Symmetries, stress and epigenesis. Genetica 89:97-119.

HALLÉ, F. 1986. Modular growth in seed plants. Philosophical Transactions of the Royal Society of London, series B Biological Sciences 313:77-87.

JANIESCH, P. 1991. Ecophysiological adaptations of higher plants in natural communities to waterlogging. In Ecological responses to environmental stresses. (J. Rozema \& J.A.C. Verkleij, eds.). Kluwer Academic Publishers, Dordrecht, p.50-60.

JOHANSEN, D.A. 1940. Plant microtechnique. McGraw-Hill, New York.

JOLY, C.A. 1996. The role of oxygen diffusion to the root system on flooding tolerance of tropical trees. Revista Brasileira de Biologia 56:375-382.

KOZLOWSKI, T.T. 1984. Responses of woody plants to flooding. In Flooding and plant growth. (T.T. Kozlowski, ed.). Academic Press, San Diego.

KUTSCHERA, U. 1991. Regulation of cell expansion. In The cytoskeletal basis of plant growth and form. (C.W. Lloyd, ed.). Academic Press, London.

LOBO, P.C. \& JOLY, C.A. 2000. Aspectos ecofisiológicos da vegetação de mata ciliar do sudeste do Brasil. In Matas Ciliares: Conservação e recuperação. (R.R. Rodrigues \& H.F. Leitão Filho, eds.). Edusp, São Paulo. p.143-157.

MEDRI, M.E., BIANCHINI, E., PIMENTA, J.A., DELGADO, M.F. \& CORREA, G.T. 1998. Aspectos morfo-anatômicos e fisiológicos de Peltophorum dubium (Spr.) Taub. submetida ao alagamento e à aplicação de etrel. Revista Brasileira de Botânica 21:261-267.

MOHR, H. 1982. Principles in plant morphogenesis. Acta Biotheoretica 31:93-111.

MORRETES, B.L. \& VENTURELLI, M. 1985. Ocorrência de "lenticelas" em folhas de Tripodanthus acutifolius (R. \& P.) Tiegh. (Loranthaceae). Revista Brasileira de Botânica 8:157-162.

PAHLICH, E. 1993. Larcher's definition of plant stress: A valuable principle for metabolic adaptibility research. Revista Brasileira de Fisiologia Vegetal 5:209-216.

PAROLIN, P. 2001. Senna reticulata, a pioner tree from amazonian várzea floodplains. The Botanical Review 67:239-254.
PETERSON, R.L. \& FARQUHAR, M.L. 1996. Root hairs: Specialized tubular cells extending root surfaces. The Botanical Review 62:1-40.

ROGGE, G.D., PIMENTA, J.A., BIANCHINI, E., MEDRI, M.E., COLLI, S. \& ALVES, L.M.T. 1998. Metabolismo respiratório de raízes de espécies arbóreas tropicais submetidas à inundação. Revista Brasileira de Botânica 21:153-158.

RUBIN FILHO, C.J. 1997. Respostas fisiológicas e anatômicas de plantas jovens de Inga vera Willd. (Leguminosae Mimosoideae) sob condições de alagamento. Tese doutorado, Universidade Federal de São Carlos, São Carlos.

SANTIAGO, E.F. 2002. Plasticidade adaptativa de plântulas de floresta ciliar do Rio da Prata, Município de JardimMS, Tese doutorado, Universidade Estadual Paulista, Rio Claro.

SATTLER, R. 1996. Process morphology: Structural dynamics in development and evolution. Canadian Journal of Botany 70:708-714.

SHARPE, P.J.H. \& RYKIEL JUNIOR, J.E. 1991. Modelling integrated response of plant to multiple stress. In Response of plants to multiple stresses. (A. Mooney, W. Winner \& E.J. Pell, eds.). Academic Press, London, p.206-223.

SCATENA, V.L. \& MENEZES, N.L. 1996. Anatomia de raízes de Syngonanthus Ruhl. (Eriocaulaceae). Revista Brasileira de Biologia 56:333-343.

SOUZA, G.M. \& MANZATTO, G.A. 2000. Hierarquia autoorganizada em sistemas biológicos. In Auto organização. (I.M.L. D’Ottaviano \& M.E.Q. Gonzales, eds.). Unicamp, Campinas. 30:153-173.

THOMAS, G.B. 1969. Cálculo II. Ed. Ao livro Técnico, Rio de Janeiro.

VARTAPETIAN, B.B. \& JACKSON, M.B. 1997. Plant adaptation to anaerobic stress. Annals of Botany (Supplement A) 79:3-20.

VASCONCELOS, J.C. \& COUTINHO, M.C.P. 1960. Noções sobre anatomia de plantas superiores. Serviço de Informação Agrícola, Lisboa.

VIEIRA, S. \& HOFFMANN, R. 1989. Estatística experimental. Atlas, São Paulo.

WAMPLE, R.L. \& REID, D.M. 1979. The role of endogenous auxins and ethylene in the formation of adventitious roots and hypocotyl hypertrophy in flooded sunflower plants (Helianthus annus L.) Physiologia Plantarum 45:219-226. 